\title{
Erratum
}

\section{Laser-Induced Self-Phase Modulation in Polymeric Films}

\author{
L. N. Binh ${ }^{1}$, X. Dai ${ }^{1}$, and Y. H. Ja ${ }^{2}$ \\ ${ }^{1}$ Department of Electrical and Computer Systems Engineering, Monash University, \\ Clayton, Victoria 3168, Australia \\ ${ }^{2}$ Telecom Australia Research Laboratories, 770 Blackburn Road, Clayton, \\ Victoria 3168, Australia
}

Appl. Phys. B 49, 393-396 (1989)

In Figs. 3, 4 and 5 of this paper the units for the horizontal axis $I_{0}$ should be Watt $/ \mathrm{cm}^{2}$ and not $\mathrm{MW} / \mathrm{cm}^{2}$ as originally indicated.

Further comment. This shows that the polymeric films exhibit a gigantic nonlinear property. 